\title{
РЕФОРМИРОВАНИЕ УПРАВЛЕНИЯ СОЦИАЛЬНО-ЭКОНОМИЧЕСКОЙ И ПРАВОВОЙ СИСТЕМЫ НА КАВКАЗСКИХ МИНЕРАЛЬНЫХ ВОДАХ (КОНЕЦ 50-X - В 60-е гг. XIX В.).
}

Исследовано влияние реформирования социальной сферы в империи периода Александра II в аспекте курортной. Рассмотрена роль личности в совершенствовании курортного дела. Впервые отмечены различные подходы наместников Н. Н. Муравьева и А. И. Барятинского к модернизации курортного дела на Кавминводах. Акцентировано внимание на влияние военно-командного состава на Кавказе в вопросах совершенствования управления курортами. Исследованы причины реформирования управления КМВ в форме контрагентства Выявлены основания для перевода системы управления из казны в частные руки. Проанализированы оценки в историографии проблемы зффективности модернизации управления курортами и их содержания. Приведень мнения об особой форме контракта и об обязательствах в разделении полномочий в управлении и финансировании между частным лицом и государством. Определен срок контрагентства. Раскрыта позиция генерала, князя А. И. Барятинского в понимании ценности лечебной местности КМВ для здоровья нации, создание условий не только для развития, но и для безопасности регио- на. Отмечены принципы наместника в определении деловых качеств в подборе кандидатуры на частное контрагентство Вод. Подтверждена верность выбора по избранию делового, инициативного и успешного в вопросах коммерции на Юге России, по сути государственника, по отношению к делу, - д. ст. с. Н. А. Новосельского Подчеркивается, что для реализации научного подхода в пользовании Кавказскими водами был также применен профессиональный подход в выборе на пост директора KMB молодого известного доктора медицины Московского университета С. А. Смирнова, что и повлияло на научный подход в управлении лечебной местностью.

Проанализированы причины введения нового местного органа власти в курортном регионе и установление административного контроля над частной эксплуатацией KMB.

Ключевые слова: Кавказские Минеральные Воды, реформы управления, Кавказское наместничество, контрагентство, дирекция, Терская область, Пятигорский округ.

\section{I. Krasnokutskaya, V. S. Krasnokutskij}

The article studies the influence of reforming the social sphere in the Empire of the period of Alexander II in the aspect of the resort area. The role of personality in improving the resort business is considered. The study highlights different approaches of the governors of N. N. Murav'eva and $A$. I. Baryatinsky to the modernization of the resort on the Caucasus Mineral Waters. Attention is focused on the influence of the military command staff in the Caucasus in improving the management of resorts. The causes of the reform of the CMW management in the form of counteragent are investigated. The reason for the transfer of system control from the Treasury to private hands is identified. The analysis of the evaluation in the historiography of researchers of the problem from contemporaries to the present day, as well as opinions about the effectiveness of modernization and saving public funds is carried out. The opinion about the special form of the contract and the obligations in division of powers in management and financing between the private person and the state is given. The term of the counterparty is defined. The position of the General, Prince Baryatinsky, as regards the understanding of the value of the medical area of the CMW for the health of the nation, the creation of conditions for the development, but also for the security of the region, is studied. The principles of the Governor in the definition of competencies in the selection of candidates for private counteragency of the Waters are noted. The study proves the correctness of the choice for the election of business, initiative and successful in matters of Commerce in the South of Russia, in fact a statesman, in relation to the case of state councilor N. A. Novoselsky. It is emphasized that for the implementation of the scientific approach in the use of the Caucasus Waters a professional approach was also applied in the selection of the post of Director of the Moscow University of medicine of the young well-known doctor of medicine $\mathrm{S}$. Smirnov, which influenced the scientific approach in the management of therapeutic areas.

The reasons for the introduction of a new local authority in the resort region and the establishment of administrative control over the private operation of the CMW are analyzed.

Key words: Caucasus Spas, management reforms Caucasus vicegerency, counterparty, directorate, Terek territory, Pyatigorsk district. 
Развитие курортов Кавказских Минеральных Вод, их административно-правовая база складывалась на протяжении более чем двух веков. Государственная политика в области курортного строительства в первую очередь была всегда направлена на развитие их уникальных возможностей.

Актуальность изучения проблемы продиктована новыми реалиями хозяйствования, переходом на рыночные отношения, складывающейся многоведомственностью в управлении.

В этой связи учет социальных, экономических геополитических, экономических особенностей развития региона - главные условия в успешном и эфффективном функционировании курортов.

Управление курортным регионом складывалось длительно: от назначения одного административного лица к созданию системы управления Кавказскими Минеральными Водами, которая несколько раз за XIX в. реформировалось. Бесспорно, что государственные мужи России, министры внутренних дел, государственных имуществ, главноначальствующие на Кавказе и в Грузии находились в постоянном поиске совершенствования путей, форм и методов управления курортной местностью в целях дальнейшего развития. Исторический путь становления и развития Кавминвод показывает, что только 22 года они находились в ведении частных лиц. Деятельность временных владельцев - контрагентов преследовала, прежде всего, извлечение прибыли.

Следовательно, все новации по управлению на местах реализовывали региональные органы управления в лице командующих на Кавказской линии, генерал-губернаторов, а также самих директоров курортов. Почти весь XIX в. проводниками государственной политики на Кавказе по курортам были представители военно-гражданской администрации - кадрового корпуса правительства.

В условиях ещё немирного Северного Кавказа неустроенную и лишь затратную окраину Российской империи предстояло сделать курортом государственного значения.

Определяющим в этом вопросе был Указ 1803 г императора Александра I, навсегда признавший Кавказские Минеральные Воды государственным достоянием и поставивший их под правительственный надзор. Перспективной целью он считал обретение своих Российских курортов по типу тогда уже широко известных в Европе французских, итальянских, немецких [1, с. 252]

Необходимо отметить последовательность русского императорского двора и личное участие императоров в формировании законодательной основы деятельности курорта, в подборе и расстановке кадров, финансировании различных проектов.

Известно, что император Николай I после посещения КМВ в 1837 г., лично убедившись в ценности мест для России, удовлетворенный состоянием развития молодого курорта, принял решение отпускать ежегодно на их устройство 200 тысяч руб. Фактически стал инициатором образования постоянного фронда (капитала) Вод $[8$, с. 20].
Ратуя за развитие отечественного курорта, Николай I даже пошел на такую меру как запрещение российской элите в 30-е - 40-е гг. XIX в. выезда на лечение и отдых на заграничные курорты $[8$, c. 21$]$.

Такая заинтересованная политика была продолжена и в царствование Александра II и Александра III.

Однако только при императоре Николае II будет создан специальный фонд курорта (капитал), в котором сосредоточивались все средства от эксплуатации Вод, а также оставались ежегодные безвозвратные субсидии государства [8, c. 41]. Это и позволило на высоком уровне развивать инфраструктуру курорта, заниматься благоустройством - превратить КМВ в лучшую отечественную здравницу к 100-летию ее основания.

Но вернёмся к концу 50-х гг. XIX в. В этот период усилия правительственных органов в лице наместничества Кавказского, Кавказского комитета, не позволяли развить лечебную местность в силу того, что посетителей пугала близость военных действий (неоправданная), отсутствие качественных путей сообщения, дороговизна жизни, неустройство Вод. Число посетителей снизилось. За период подчинения наместничеству с 1847 г число посетителей в среднем составляло ежегодно в течение 12 лет по 600 человек (по подсчетам автора). Такая определенная стабильность, вышестоящими органами по сути определялась как стагнация, которую многие современники считали явным застоем. Ветшало материально-техническое оснащение [10, с. 109]. Технологии в услугах на курортах отставали от западных. Лечебная местность оставалась затратной, убыточной для казны, а также малопосещаемой $[12, \text { с. 144] }]^{1}$

Этот курортный регион являлся по-прежнему периферийным, но особым с точки зрения своей курортно-лечебной значимости для всей страны. В Российской империи период контрагентства совпадает со временем реформ императора Александра II. Государство нуждалось в модернизации всех отраслей народного хозяйства и переводе их на капиталистический путь развития. Наряду с государственными системами управления расширялись институты общественного самоуправления городов и сельской местности. Получили дальнейшее развитие отдельные сферы в отраслях государственного хозяйства, где отдавалось предпочтение частному капиталу, проходила передача отдельных государственных секторов в частные руки.

Официальная медицинская система характеризовалась в основном военно-медицинскими учреждениями, а также частными клиниками, с практикой частных врачей. Региональными органами власти были губернские врачебные управы, где специального куратора курортной области не предусматривалось. В наместничестве Кавказском 2-й департамент общих дел главного управления наместничества обязан был осущест-

1 Посещаемость по данным Н. А. Кулибина составляла 390 лиц в 1854 г. и 663 в 1857 г. 
влять контроль за положением на Кавказских Минеральных Водах. По Положению «О Кавказских Минеральных Водах» 1858 г. утвержденному наместником А. И. Барятинским военный надзор за порядком на водах осуществлял командующий на Кавказской линии, а за гражданской частью Ставропольский гражданский губернатор [2] Дело благоустройства Кавминвод с 1847 г. волею наместника князя М. С. Воронцова значительно улучшилось. Однако к концу его правления ему не удалось достичь желаемого уровня для посетителей Вод. Военные заботы ставили жесткие границы к его деятельности по отношению к Кавказским Минеральным Водам [11, с. 62]

По-особому буржуазные реформы коснулись курортной сферы Северного Кавказа. В государственном медицинском учреждении сопутствующие курортные услуги Кавказских Минеральных Вод, такие как транспорт, торговля и гостиничное дело были беспроигрышны в плане прибыли и потому всегда находились желающие в их предоставлении. Однако передача лечебных услуг с бальнеолечебницами, источниками, парками в частные руки не практиковалась, так как все это принадлежало казне [8, с. 222].

Мысль о передаче Вод в частные руки была не нова. В этом плане интересна, оставленная без внимания, инициатива И. Дебу. Еще в конце 20-х г XIX в. командующий правым фрлангом Кавказской линии, генерал-майор Иосиф Дебу предлагал обратиться к капиталистам с тем, чтобы найти желающих вложить в устройство «потребное число денег, с тем, чтобы в течение 25-летнего срока пользоваться всеми доходами и выгодами, могущими от них произойти» [5, с. 550]. Он считал, что этот способ в перспективе принесёт пользу для казны.

Однако этот проект по вложению частных инвестиций в развитие курорта станет возможным лишь в период реформ 60-70-х гг. XIX в

Таким образом, передача Кавказских Минеральных Вод в составе четырех курортов (Пятигорск, Кисловодск, Железноводск, Ессентуки), медицинского учреждения Министерства внутренних дел и наместничества Кавказского с 60-х г. XIX в. в контрагентство, т.е. во временную эксплуатацию частным лицам, - отвечала вызовам времени.

В историографии проблемы существуют различные точки зрения на причины передачи курортов КМВ в частное владение, пусть даже и временное, а также на деятельность исполнителей-контрагентов и директоров Вод.

Особенно ценны мнения современников, специалистов Ученого горного комитета и медиков курорта конца XIX - начала XX в. (М. К. Милютин (1879 г.) [6], В. С. Богословский (1881 г.) [4], С. Кулибин (1896 г.) [10, с. 23], Святловский (1898 г.) [18], К. А. Скальковский (1906 г.) [21] указывали на безынициативность казенной дирекции и выражали надежду на частную инициативу в этом вопросе. Называли данный период «эрой нового существования KMB» [6, с. 51]. Исследователи советского периода указывали, что это было вынужденной мерой из-за трудностей финансового характера, связанного с поражением в Крымской войне и завершением длительного военного конфллита на северо-востоке Северного Кавказа (Пантелеев 1955 [13], Кривобоков Н. Г. [9]). Учёные-историки постсоветского времени пытаются объяснить френомен контрагентства также с позиции объективных причин. Так О. И. Серегина [20], Н. Б. Семина [19] указывают на то, что центральная власть решила, что отдав курорты в частные руки, она справится с проблемой устранения убыточности статьи бюджета, связанной с содержанием курорта, а также частное лицо будет заботиться не только о лечебной базе но и об инфраструктуре КMB.

Е. В. Белозерова [3], Ю. Ульянова [22] считают, что причина временной передачи курортов в частную эксплуатацию являлась неким Российским экспериментом, желанием получить прибыль с курорта. Для этого необходимо было создать его индустрию (С. С. Лазарян [11, с. 196]).

Каждое из этих мнений раскрывает лишь отдельные взгляды, повлиявшие на столь кардинально принятое решение, поддержанное всеми институтами властвующих структур. Несомненно в этом вопросе для принятия предложения князя Барятинского стал авторитет личности наместника, победителя, завершившего войну на северо-востоке Северного Кавказа. Заметим, что императоры всецело доверяли своим ставленникам в таком деликатном деле как курортное. Так, это было в 1846 г. с переводом курортов КМВ в ведение наместничества при М. С. Воронцове, введение дирекции, несмотря на многочисленный состав и явную преждевременность [8, с. 31-32].

В 1861 г. поддержаны шаги по упразднению затратной курортной бюрократической машины, отказу от государственного управления с передачей на содержание в частные руки. Данные преобразования были связаны с неудобствами казенного управления, и коренных изменений не последовало $[4$, с. 14-17].

Дпя нас важна точка зрения инициатора этого шага наместника Кавказского князя А. И. Барятинского, который считал, что главное обстоятельство, мешающее развитию Кавказских Минеральных Вод, «заключается в том, что Водами заведует правительственная или казенная администрация [12]. Удалось выявить и причину, и повод такого на первый взгляд неординарного, нового решения.

До 1856 г. наместник Кавказский Н. Н. Муравьев предлагал, чтобы облегчить фринансовое бремя с казны передать Воды в местное управление $[8$, с. 32-33]. Такое решение могло перечеркнуть перспективы будущего Вод в качестве курортов. Министерство государственных имуществ летом 1856 г. направило для межевания местности комиссию, которая едва их не упразднила'. Тогда же было признано, что Кавказские

1 В состав комиссии входили: Управляющий Экспедицией министерства гос. имуществ М. И. Муравьев (младший брат наместника), заведующий медицинской частью на Кавказе и чиновник особых поручений Ф. А. Баталин, офицеры межевого конкурса С. М. Старовский и А. П. Кокин 
Минеральные Воды могут давать казне лишь убыток. Как положительный пример приводились Боржомские воды, на их устройство потрачено до 80 тыс. руб., а ежегодный доход был равен 420 тыс. руб. [18, с. 27].

Новый наместник Кавказский князь А. И. Барятинский (с июля 1856 г.), глубоко осознававший ценность Кавказских Вод для России, «всё это перерешил». Направленная лично им ревизия под началом гражданского генерал-губернатора Ставропольской губернии Н. Н. Бренчанинова ${ }^{1}$, «открыла, что причина упадка курортов находилась в ясном и ничем неизвинительным бездействии дирекции КМВ» $[18$, с. 28]2. Князь А. И. Барятинский изменил деятельность курортов и дал им совершенно другое направление. Прежде всего, он принял предложение надзирающего по долгу службы за КМВ и проверивших их генерал-губернатора Ставропольской губернии Н.Н. Бренчанинова о направлении врачей, определяемых к Водам для изучения устройства и порядков на лучших западноевропейских лечебных местах. Тогда же наместник с одобрения Кавказского комитета и по указу императора России Александра II реформировал казенное управление на частное [17, л. 163-174].

Обращаясь к императору за разрешением на передачу частного управления $\mathrm{KMB}$, князь А. И. Барятинский писал, что он глубоко убежден, что $c$ переменой казенной администрации на частную правительство вернее достигнет цели, которая бесплодно преследуется им десятки лет. Он приводит убедительные доводы по получению от новой дирекции выгод:

- останутся в сбережении суммы государственного казначейства, которые отпускаются в виде прибавочных окладов гражданских чиновников, за выслугу им на Кавказе установленных сроков

- прекратится отпуск из комиссариата (военного ведомства) содержания военным чинам дирекции, определенные штатом 1847 г. [14, с. 66].

Кавказский комитет правительства Российской империи разделил мнение и поддержал обращение наместника Кавказского в том, что управление Кавказскими Минеральными Водами, предоставленное частному лицу, если это лицо опытное в подобном деле и может располагать достаточными денежными средствами, принесет гораздо больше пользы, чем управление казенное, обязанное действовать по установленным формам и правилам [17]. Комитет также считал эту меру - «управление частного содержателя» полезной

По своей правовой сущности договор частного управления не имел прямых аналогов с известными дореволюционному гражданскому праву договорами. Однако он ближе всего соответствовал

${ }^{1}$ По Положению «О временном отделении по делам гражданского устройства края» наместничество Кавказское определялось управляющим Кавказскими Минеральными Водами [2, с. 32]

2 Последний директор Вод, он же военный губернатор КMB, генерал-майор, барон Леонард Карлович $\mathrm{Y}_{\mathrm{H}}$ герн-Штернберг. договору казенного порядка, но не полностью Это позволяет видеть в нем совершенно особую форму гражданско-правовой фиксации отношений между контрагентом и правительством [3].

Итак, реформирование ряда сфер Российской социально-экономической и правовой системы коснулось и отдаленной от центра страны специфической для государства курортной сферы Кавказских Минеральных Вод. Очевидно, что правительство предполагало, что частный интерес и получение прибыли станет главным рычагом, побудительным мотивом к совершенствованию курортного дела в целом, возможно, позволит создать курортную индустрию в России

Наместник Кавказа А. И. Барятинский посчитал целесообразным отдать все группы КМВ одному лицу. Он остановился на кандидатуре преуспевающего известного предпринимателя Юга России действительного статского советника Н. А. Новосельского, крупного владельца акционерного общества «Пароходства и торговли на Волге и Каспии», способного принять на особых условиях в свое заведование курорты Кавминвод с 1861 по 1869 гг. [16]. Договор вступил в силу с декабря 1861 г. Контрагентство должно было решить вопрос преодоления убыточности Кавказских Вод.

Это был новый этап в развитии лечебниц КМВ. Вменялась забота об улучшении состояния Вод и возведении их на ту ступень благоустройства, на которой лечебная местность соответствовала бы требованиям посетителей Вод.

Контрагент брал в частное управление Кавминводы, однако основные расходы оставляло за собой государство. При поддержке им основных затрат: прежде всего штата дирекции и содержания минеральных источников, военной рабочей роты. Частнику была полностью отдана вся финансовая составляющая, включая доходы от услуг.

Передача Управления КМВ частному лицу означала устранение правительственной администрации в регионе. В таких условиях, когда ещё на Северном Кавказе проводились мероприятия, связанные с «замирением» края невозможно было оставить его без администрации представлявшей государственную власть [20, с. 63]. А. И. Барятинский своим приказом ввел военную власть, учредив Пятигорский округ, во главе с начальником генералом, который включал Кавказские Минеральные Воды. На эту должность назначался генерал главнокомандующим Кавказской армией и утверждался императором. В его обязанности входило обеспечение внутренней безопасности вплоть до применения войск. А также прямая связь с командующим войсками Терской области. Кроме этого, он обязан был наблюдать за лечением воинских чинов, чтобы они не оставались на курортах дольше положенного времени. Военный начальник округа пользовался властью и правами начальника дивизии в отношении войск, расквартированных для военного постоя в районе КМВ [20, с. 63]. Ещё раньше, в 1860 г., А. И. Барятинский внёс предложение Минеральные Воды, находящиеся в Ставропольской губернии разделить - Пятигорск и Желез- 
новодск оставить в Ставропольской губернии, а Кисловодск и Ессентуки передать во вновь учрежденную Терскую область [8, с. 35].

Согласно договору аренды, все находившиеся при Водах земли, хозяйственные постройки сами минеральные источники с устройствами в них отдавались в полное ведение контрагента на 8 лет. Новая частная администрация Вод приносила определенные выгоды для государства в вопросах найма специалистов управления КMB т.к. военные чины Дирекции Вод теперь упразднялись (от генерала вплоть до младших офицеров). Н. А. Новосельский в свою очередь пригласил на должность директора Кавказских Минеральных Вод известного прогрессивного столичного врача С. А. Смирнова (1819-1911)', который возглавил новое управление с 1862 г. КМВ вступило в частное управление.

Контрагент был обязан содержать всё казенное имущество в исправности, производить ремонт его за свой счёт. На возведение новых сооружений должен был «спрашивать лично разрешение наместника» $[15$, с. 187].

Авторитетное мнение наместника Кавказского, несмотря на новизну подхода в управлении, было всецело поддержано всеми властными структурами правительства России.

Итак, наместничество Кавказское, в ведении которого находились курорты КМВ с 1846 г., в кон- це 50-х гг. XIX в. было озабочено ухудшением материально-технической базы, благоустройством, снижением посещаемости, убыточностью.

Региональные органы власти в лице наместников стремились ликвидировать отсталость путем совершенствования управления Водами. Необходимо было принимать кардинальное решение: либо передавать их в местное управление, что означало закрыть путь их развития ко Всероссийской здравнице, либо новый путь - гражданского управления с передачей в частные руки.

В условиях фринансового кризиса после завершения длительного военного конфликта на северо-востоке Северного Кавказа, Крымской войны, введения временного гражданского управления Кавказом и реформированием социально-экономической и правовой системы в стране наместник Кавказский, князь А. И. Барятинский принял решение по кардинальному изменению системы управления казенными курортами. Доверил лечебницу КМВ известному предпринимателю на Юге России на условиях договора контрагентства Н. Н. Новосельскому сроком на 8 лет. Для реализации договора в качестве директора управления КМВ был привлечен профессионал-медик - доктор медицины С. А. Смирнов, что и определило перспективы их научного развития.

\section{Источники и литература}

1. Акты собранные Кавказской археографической комиссией (АКАК). Т.2. Тифлис: Типография Главного Управления наместника Кавказского, 1868. 1238 с.

2. АКАК. Т.12. Тифлис: Типография Главного Управления наместника Кавказского, 1885. 1546 с.

3. Белозерова Е. В. Государственно-правовая политика Российской Империи в отношении курортов Кавказских Минеральных Вод. URL: https://search.rsl.ru/ru/record/01004840640 (Дата обращения: 27.09.2018).

4. Богословский В. С. Пятигорск и с ним смежные Минеральные Воды (с четырымя планами). М.: [б.и.], 1881. 285 с.

5. Дебу И. О Кавказской линии и присоединенном к ней Черноморском войске или общие замечания о поселенных полках, ограждающих Кавказскую линию, и о соседственных горских народах. СПб.: [б.и.], 1829. 463 с.

6. Кавказские Минеральные Воды (Путеводитель). 2-е исправленное и дополненное издание. Составитель доктор М. Милютин. М.: Товарищество Клайн, 1879. 399 с.

7. Копылова Е.Э., Краснокутская Л.И. Становление и развитие военно-медицинской службы на Кавказских Минеральных Водах (1803-2007). Ессентуки: Издательский Дом, 2007. 222 с

8. Краснокутская Л. И., Михайленко В. И. Управление Кавказскими Минеральными Водами. Пятигорск: Вестник Кавказа, 2004. $160 \mathrm{c}$.

9. Кривобоков Н. Г. Кавказские Минеральные Воды. Пятигорск, 1994. 184 с.

10. Кулибин С. Очерки истории развития Кавказских Минеральных Вод (1817-1895 г.). СПб.: Типография Киршбаума, 1896. $198 \mathrm{c}$.

11. Лазарян С. С. Становление предпринимательства в регионе КМВ 1780-1917 гг. Пятигорск: Спецпечать, 2003. $196 \mathrm{c}$.

12. О передаче Кавказских Минеральных Вод на содержание Н. А. Новосельскому на основании утвержденных правил // Журнал Кавказского комитета. 1862. 3-10 апреля 1862 г. // РГИА. Ф.1268. Оп. 26. Д. 14. Л. 153-174.

13. Пантелеев И. Я. Очерк истории изучения и развития Кавказских Минеральных Вод. М.: Госгеолтехиздат, 1955 $204 \mathrm{c}$.

14. Пятигорск в исторических документах 1803-1917. Ставрополь: Книжное издательство, 1985. 352 с

15. Пятигорск в исторических очерках. История города Пятигорска с древнейших времен до 1917 г. / С. В. Богпачев, В. А. Кузнецов, Н. В. Маркелов / Под общей редакцией Н. В. Маркелова. Пятигорск: Снег, 2014. 320 с

16. РГИА.Ф.1264.Оп.26.Д.34.

17. РГИА.Ф.1268.Оп.26.Д.24.

1 Энергичный новатор, в возрасте 40 лет он защитил диссертацию на соискание степени доктора медицинь в Московском госуниверситете им. Ломоносова, где возглавлял «Общество Московских врачей». 
18. Святловский С. В. Кавказские Минеральные Воды. Справочная книга. К 100-летию курортов КМВ. Екатериноспав: М. С. Копылов, 1898. 308 с.

19. Семина Н. Б. Управление культурными процессами на Кавказских Минеральных Водах в XIX - начале XX BB. URL: http://www.dissercat.com/content/upravlenie-kulturnymi-protsessami-na-kavkazskikh-mineralnykh-vodakh-v-xix-nachale-xxvv. (Дата обращения: 27.09.2018).

20. Серегина О. И. Курорты Северного Кавказа в военной, экономической и культурной жизни России в конце XVIII начале XX вв. [Электронный ресурc]. URL: http://www.dissercat.com/content/kurorty-severnogo-kavkaza-v-voennoiekonomicheskoi-i-kulturnoi-zhizni-rossii-v-kontse-xviii-. (Дата обращения: 27.09.2018).

21. Скальковский К. А. Воспоминания молодости. 1843-1869. СПб.: А. С. Суворина, 1906. 410 с

22. Ульянова Ю. С. Становление и развитие управления курортами Кавказских Минеральных Вод (конец XVIII В. 1900 г.). URL: http://www.vipstd.ru/index.php/серия-гуманитарные-науки/серия-гуманитарные-науки-2016/гуманитарные-науки-2016-июнь/572-hum-14. (Дата обращения: 27.09.2018).

\section{References}

1. Akty sobrannye Kavkazskoj arkheograficheskoj komissiej (Acts Collected by the Caucasus Archaeological Commission). Vol.2.Tiflis: Caucasian governor printing house, 1868. 1238 p. (In Russian).

2. AKAK.T.12.Tiflis: Caucasian governor printing house, 1885. 1546 p. (In Russian).

3. Belozerova E. V. Gosudarstvenno-pravovaya politika Rossijskoj Imperii v otnoshenii kurortov Kavkazskikh Mineral'nykh Vod (State and Legal Policy of the Russian Empire in Relation to the Resorts of the Caucasus Mineral Waters) URL: https:// search.rsl.ru/ru/record/01004840640. (Accessed: 27.09.2018). (In Russian).

4. Bogoslovskij V. S. Pyatigorskie is nimi smezhnye Mineral'nye vody (Pyatigorsk and Adjacent Mineral Waters). Moscow, 1881. 285 p. (In Russian).

5. Debu I. O Kavkazskoj linii i prisoedinennom $\mathrm{k}$ nej CHernomorskom vojske ili obshhie zamechaniya o poselennykh polkakh, ograzhdayushhikh Kavkazskuyu liniyu, i o sosedstvennykh gorskikh narodakh (On the Caucasus Line and the Black Sea Army Attached to it or the General Remarks on Settlement Regiments Protecting the Caucasian Line and on the Neighboring Mountain People). St.Petersburg, 1829. 463 p. (In Russian).

6. Kavkazskie Mineral'nye Vody (Putevoditel') (Caucasus Mineral Waters (Guide). Moscow: Partnership Kline, 1879. 399 p. (In Russian).

7. Kopylova E. Eh., Krasnokutskaya L. I. Stanovlenie i razvitie voenno-meditsinskoj sluzhby na Kavkazskikh Mineral'nykh Vodakh (1803-2007) (Formation and Development of Military Medical Service in the Caucasus Mineral Waters (1803-2007). Essentuki: Izdatel'skij Dom, 2007. 222 p. (In Russian).

8. Krasnokutskaya L. I., Mikhajlenko V. I. Upravlenie Kavkazskimi Mineral'nymi Vodami (Management of Caucasus Mineral Waters). Pyatigorsk: Vestnik Kavkaza, 2004. 160 p. (In Russian).

9. Krivobokov N. G. Kavkazskie Mineral'nye Vody (Caucasus Mineral Waters). Pyatigorsk, 1994. 184 p. (In Russian).

10. Kulibin S. Ocherki istorii razvitiya Kavkazskikh Mineral'nykh Vod (1817-1895 g.) (Essays on the History of Caucasus Mineral Waters (1817-1895). St.Petersburg, 1896. 198 p. (In Russian).

11. Lazaryan S. S. Stanovlenie predprinimatel'stva v regione KMV 1780-1917 gg. (Establishment of Entrepreneurship in the Region of CMW in 1780-1917). Pyatigorsk: Spetspechat', 2003. 196 p. (In Russian).

12. O peredache Kavkazskikh Mineral'nykh Vod na soderzhanie N. A. Novosel'skomu na osnovanii utverzhdennykh pravil (On the Transfer of the Caucasus Mineral Waters on the Maintenance of N. Novoselsky on the Basis of the Approved Rules) /I ZHurnal Kavkazskogo komiteta. 1862. April 3-10, 1862 g. //Russian State Historocal Archive (RGIA). F.1268. Inv.26. D.14 L.153-174. (In Russian)

13. Panteleev I. Ya. Ocherk istorii izucheniya i razvitiya Kavkazskikh Mineral'nykh Vod (Essay on the History of the Study and the Development of Caucasus Mineral Waters). Moscow, 1955. (In Russian).

14. Pyatigorsk v istoricheskikh dokumentakh 1803-1917 (Pyatigorsk in Historical Documents in 1803-1917). Stavropol': Knizhnoe izdatel'stvo, 1985. 352 p. (In Russian).

15. Pyatigorsk $v$ istoricheskikh ocherkakh. Istoriya goroda Pyatigorska s drevnejshikh vremen do 1917 (Pyatigorsk in Historical Essays. The History of the City of Pyatigorsk from Ancient Times to 1917) / ed by N.V. Markelov. Pyatigorsk: Sneg, 2014. 320 p. (In Russian).

16. RGIA. F.1264. Inv.26. D.34. (In Russian).

17. RGIA. F.1268. Inv.26. D.24. (In Russian).

18. Svyatlovskij S. V. Kavkazskie Mineral'nye Vody. Spravochnaya kniga. K 100-letiyu kurortov KMV (Caucasusn Mineral Waters. Handbook. To the 100th anniversary of CMW Resorts). Ekaterinoslav: M.S. Kopylov, 1898. 308 p. (In Russian).

19. Semina N. B. Upravlenie kul'turnymi protsessami na Kavkazskikh Mineral'nykh Vodakh $v$ XIX - nachale XX vv. (Management of Cultural Processes in the Caucasus Mineral Waters in the XIX - early XX Centuries) URL: http://www. dissercat.com/content/upravlenie-kulturnymi-protsessami-na-kavkazskikh-mineralnykh-vodakh-v-xix-nachale-xx-vv (Accessed: 27.09.2018). (In Russian).

20. Seregina O. I. Kurorty Severnogo Kavkaza v voennoj, ehkonomicheskoj i kul'turnoj zhizni Rossii v kontse XVIII nachale XX vV. (Resorts of the North Caucasus in the Military, Economic and Cultural Life of Russia in the Late XVIII - Early XX Centuries) URL: http://www.dissercat.com/content/kurorty-severnogo-kavkaza-v-voennoi-ekonomicheskoi-i-kulturnoizhizni-rossii-v-kontse-xviii-. (Accessed: 27.09.2018). (In Russian).

21. Skal'kovskij K. A. Vospominaniya molodosti. 1843-1869 (Memories of the Youth. 1843-1869). St.Petersburg A. S. Suvorina, 1906. 410 p. (In Russian).

22. Ul'yanova Yu. S. Stanovlenie i razvitie upravleniya kurortami Kavkazskikh Mineral'nykh Vod (konets XVIII v. $-1900 \mathrm{~g}$.) (The Formation and Development of Resort Management of the Caucasus Mineral Waters (the end XVIII century - 1900). URL: http://www.vipstd.ru/index.php/seriya-gumanitarnye-nauki/seriya-gumanitarnye-nauki-2016/gumanitarnye-nauki-2016iyun'/572-hum-14. (Accessed: 27.09.2018). (In Russian). 